\title{
PREFACE
}

The PURPose of the Berkeley Statistical Symposia, held every five years, is to stimulate research through lectures by carefully selected speakers and through prolonged personal contacts of scholars brought together from distant centers. Accordingly, particular Symposia last from four to seven weeks. On occasion, and this was the case with the Fifth Symposium, they are conducted in two parts, one in June-July, emphasizing theory, and the other in December-January, emphasizing applications. The winter part of the Fifth Symposium was held in conjunction with the 132nd Annual Meeting of the American Association for the Advancement of Science.

The Proceedings of the Symposia are intended to present a comprehensive cross-section of contemporary thinking on problems of probability and statistics and on selected fields of application. The rapid growth of research in statistics and especially in probability makes it increasingly difficult to achieve a complete coverage of the field, but sincere efforts are made to invite to the Symposia representatives of all the existing schools of thought, each individual having complete freedom of expression.

The organization of the theoretical part of the Fifth Berkeley Symposium was carried out, and the contributors were selected, with the participation of an Advisory Committee composed of Professors J. L. Doob, S. Karlin, and H. Robbins, delegated for this purpose by the American Mathematical Society and by the Institute of Mathematical Statistics. In addition, we had the assistance of Professor D. L. Burkholder, the Editor of the Annals of Mathematical Statistics. The interest of the American Mathematical Society and of the Institute of Mathematical Statistics and their help are deeply appreciated.

While a broad coverage of contemporary work in the theory of probability and statistics is difficult, the field of applications of these disciplines is currently so wide that the program of a single symposium can include no more than a few particular domains. The domains covered at the Fifth Symposium were selected on two principles. First, some applied problems appeared as subjects of studies by outstanding probabilists and statisticians invited to the Symposium on account of their work in theory. Second, an effort was made to delineate a few fields of substantive studies that appear particularly promising for probabilistic and statistical treatment. One of the most fruitful fields of this category is undoubtedly biology and problems of health. Here we profited greatly by the advice of Drs. LaMont Cole, Jerome Cornfield, F. N. David, Louis Hellman, Samuel Greenhouse, Hardin Jones, Samuel Karlin, David Krech, Lincoln Moses, Curt Stern, Michael B. Shimkin, and Cornelius Tobias. Quite a few of these colleagues are connected with the broad research activity of the National Institutes of Health and helped to bring to our attention many novel and important subfields of research. 
In the field of astronomy we are deeply indebted to Drs. N. U. Mayall, Rudolph Minkowski, and Thornton L. Page.

For advice in the field of meteorology we are grateful to Drs. Farl Droessler, James Hughes, Dwight B. Kline, Morris Neiburger, Jerome Spar, Edward P. Todd, and P. H. Wyckoff. Special thanks are due to Dr. Kenneth B. Spengler, Secretary of the American Meteorological Society.

Following the established tradition, Volume I of the present Proceedings is given to the theory of statistics. Volume II is devoted to the theory of probability. Because of the large amount of material, about 1000 pages in print, this volume had to be divided into two parts formed through a somewhat arbitrary classification of papers. Volume III includes papers related to physical sciences: astronomy, theory of control, physics, and the theory of reliability. Volume IV, on biology and problems of health, includes papers on information and brain phenomena, on chance mechanisms in live organisms, on epidemiology, on genetics, on medical diagnosis, on clinical trials, on carcinogenesis and cellular phenomena, on demography, and on ecology. Some of these subdomains are already subjects of well developed statistical treatment. Others appear to offer interesting and important possibilities.

Compared to the Proceedings of the earlier Symposia, Volume V, being entirely given to the problem of artificial weather modification, is an innovation. With the classification adopted for the first four volumes, weather modification would fit Volume III. It is assigned a special volume because of the specificity of the domain and because of its separateness from all the other fields dealt with in Volume III. Also, the novelty of the problem of weather modification, considered by itself and as a field for statistical research, indicated the desirability of producing a comprehensive coverage of the more extensive experiments. Finally, it appears probable that the readership of the material being published in Volume $\mathrm{V}$ will be essentially different from that expected to be interested in Volume III.

The fifth Symposium would not have been possible without very substantial financial support from various sources. Hearty thanks are due to Dr. Clark Kerr, President of the University of California, for a special grant made several years in advance of the Symposium. Without this grant, no planning and no initial steps for the organization of the Symposium would have been possible. This initial triggering grant of the University of California was later supplemented by the subsidy of the University Editorial Committee, without which the publication of the Proceedings, to be sold at a reasonable price, would have been a very difficult problem. To a very considerable extent, the theoretical part of the Symposium and the part concerned with physical sciences, were financed by The Program in Mathematics of the National Science Foundation, by the Air Force Office of Scientific Research, by the Army Research Office, and by the Office of Naval Research. The large program on biology and problems of health was made possible by a grant of the National Institutes of Health. The 
program on weather modification was organized using a grant of the Atmospheric Sciences Section of the National Science Foundation. Finally, we wish to record special help from the Office of Naval Research, in the form of air transportation for a number of foreign participants in the Symposium.

It is our pleasure to acknowledge gratefully the generosity of the governmental institutions enumerated. The vitality of our Symposia and the growth of the Proceedings, from 500 pages in 1945 to about 3,000 in 1965 , seem to indicate that the funds provided are being spent to fill a real need.

The problems connected with the publication of such an amount of technical material are very substantial, especially since some of the material was originally written in languages other than English and required translation. All efforts were made toward speedy publication at a reasonable price, and we are pleased to acknowledge the excellent cooperation and assistance we received from the University of California Press.

For the translation of manuscripts, we are indebted to Drs. Amiel Feinstein, Morris Friedman, and Mrs. C. Stein. We are also indebted to several of our colleagues in the Department for work connected with the preparation of manuscripts for the printer. Special thanks are due to Professors E. L. Scott, M. Loève, E. W. Barankin, to Drs. Carlos-Barbosa Dantas, W. Bühler, Nora Smiriga, Grace Yang, to Mr. Steve Stigler, and Mrs. M. Darland. We are pleased to acknowledge the technical help of Mrs. Sharlee Guise and Mrs. Carol Rule Roth.

For taking care of the many complexities of editing technical manuscripts we are deeply indebted to Miss Susan Jenkins whose patience and skill deserve superlative praise. Thanks are also due to Mrs. Virginia Thompson for her greatly appreciated assistance in the same process.

To Mr. August Frugé, the Director of the University of California Press, we extend heartfelt thanks for financial, technical, and moral support in publishing so much difficult material. Special thanks are due also to Joel Walters, Editor of the University of California Press. In spite of all our efforts, we found ourselves unable to keep up with the schedule of publication proposed by the Press, but we must thank them for helping us to keep the delays at a minimum and for producing a publication in accordance with the usual excellent standards of the University of California Press.

Many thanks are due to our Administrative Assistant, Miss M. Genelly for taking care of many financial and organizational difficulties. For transportation, housing, and other logistic problems connected with the organization of the meeting itself, very valuable assistance was received from the staff of the Laboratory and in particular from Miss June Haynes and Mrs. J. Lovasich.

As was the case on many earlier similar occasions, for supervising and taking care of the innumerable intricacies of local organization we are deeply indebted to our colleague Professor Elizabeth L. Scott. It is a pleasure to express here our deepest appreciation. 
Last but not least we wish to thank the Department of Statistics of the University of California, Berkeley, and all our colleagues therein, for their sympathetic attitude and help. Particular thanks are due to David Blackwell.

During the winter part of the Fifth Symposium, the Statistical Laboratory lost one of its organizers as well as one of its most active members. Our colleague and cordial friend, Professor Evelyn Fix died of a heart attack on December 30, only a few hours after she acted as one of the hostesses at the banquet of the Symposium. Sit ei terra levis!

Lucien Le Cam

July, 1967
JERzy NeYmaN

Director, Statistical Laboratory

\section{PREFACE TO VOLUME V}

The idea of organizing a special Weather Modification Section of the Fifth Symposium, and of publishing a separate volume of the Proceedings, specifically given to weather control problems, occurred to us in the fall of 1964 as a result of studying the seven voluminous annual reports on the Swiss experiment Grossversuch III. Even though the primary purpose of this experiment was hail prevention, the reports contain a wealth of data on rainfall and on other collateral factors. The analysis we performed indicated not only the presence of real effects of seeding on rainfall, but also the puzzling circumstance that in some not clearly defined conditions these effects are positive and in some other conditions they are likely to be negative. Since over the last two decades a number of randomized cloud seeding experiments have been carried out, it appeared timely to organize a systematic review of as many of them as practicable. Jointly they may reveal an intelligible pattern of the effects of cloud seeding, even though in separate experiments these effects seem inconclusive or contradictory.

Weather control is a new field of experimentation with peculiarities not encountered in other fields which stimulated the development of experimental designs and of statistical techniques that are now available. Our hope is that the Weather Modification Section of the Symposium and the present volume will serve as a stimulus for novel statistical research, theoretical as well as empirical, which will be beneficial both to statistics and to applied meteorology. It was a pleasure to find that the above ideas met with the approval of the Weather Modification Program of the National Science Foundation whose financial help is gratefully acknowledged.

As we see it, the inspiration of fresh statistical research, and also an advance in the understanding of the complex reactions of the weather to external stimuli, 
depend very much on ready availability of observational data which could serve for verification of various tentative hypotheses that may be formulated. Thus, an effort was made to assemble a substantial collection of experimental results on rainfall and on some collateral factors. This collection is published at the end of the volume.

To our knowledge, the present review of weather control studies is the fifth to be published. The first review, which was brought to our attention by Dr. George Steck of Sandia Corporation, appeared more than 70 years ago. The relevant article, written by M. W. Harrington under the title "Weather making, ancient and modern," is contained in the Smithsonian Report, 1894, pp. 249-270. The paper makes a distinction between scientific methods of rain making and those based on superstition. It appears that already at that time some of the "scientific" methods had been patented. The paper is interesting and at times amusing reading.

The second published summary of weather modification studies seems to be the controversial Final Report of the Advisory Committee on Weather Control, Vol. 1 and 2, Washington, D. C., 1957. This was followed by two reports of the Panel on Weather and Climate Modification of the National Academy of Sciences-National Research Council, the Preliminary Report of 1964 (NASNRC Publication 1236), and the two volume Final Report of 1966 (NAS-NRC Publication 1350). Even though contemporaneous and concerned with the same general domain, the two volumes of the Final Report of the Panel have little in common with the present volume of the Proceedings. There is no duplication.

Lucien M. LeCam Jerzy Neyman Elizabeth L. Scott 
